\title{
GEOTECNOLOGIAS PARA MAPEAR LAVOURAS DE CAFÉ NOS ESTADOS DE MINAS GERAIS E SÃO PAULO ${ }^{1}$
}

\section{MAURICIO A. MOREIRA ${ }^{2}$, BERNARDO F. T. RUDORFF ${ }^{3}$, MARCO A. BARROS ${ }^{4}$, VIVIANE G. C. DE FARIA ${ }^{5}$, MARCO ADAMI ${ }^{6}$}

\begin{abstract}
RESUMO: O uso operacional de imagens de satélites de sensoriamento remoto para mapear lavouras de café em grandes áreas, para fins de obtenção de estatísticas agrícolas confiáveis e oportunas, ainda se encontra em desenvolvimento. Diversos são os fatores que dificultam a correta identificação e mapeamento do parque cafeeiro. Contudo, os avanços tecnológicos observados nos últimos anos em termos de aquisição de imagens com melhor qualidade e em maior quantidade, bem como o desenvolvimento de novas ferramentas de análise, propiciam o desenvolvimento de um método operacional que pode contribuir na formação das estatísticas agrícolas oficiais do café no Brasil. Neste sentido, o presente trabalho tem por objetivo relatar a metodologia e apresentar os resultados do mapeamento das áreas cultivadas com café nos Estados de Minas Gerais e São Paulo, utilizando imagens de sensoriamento remoto e técnicas de geoprocessamento. A abordagem metodológica consiste em quatro fases: a) restauração das imagens e georreferenciamento; b) classificação não supervisionada; c) interpretação visual na tela do computador para minimizar erros de omissão e inclusão, e d) determinação da área cultivada com café. Os resultados indicaram que a metodologia utilizada foi adequada para o mapeamento das lavouras de café de Minas Gerais e São Paulo.
\end{abstract}

PALAVRAS-CHAVE: sensoriamento remoto, imagens de satélite, geoprocessamento, estatísticas agrícolas.

\section{GEOTECNOLOGIES TO MAP COFFEE FIELDS IN THE STATES OF MINAS GERAIS AND SÃO PAULO}

\begin{abstract}
The operational use of remote sensing images to map coffee fields in large areas, in order to obtain reliable and timely agricultural statistics, is still under development. Several factors raise difficulties to correctly identify and map the coffee crop. However, technological advances observed in the last years, in terms of image acquisition with improved quality and greater quantity, as well as the development of new tools for image analysis, is favoring the development of an operational method that may contribute to establish the official coffee crop statistics in Brazil. Therefore, the present work has the objective to describe the method and to present the result of the coffee fields mapped in the states of Minas Gerais and São Paulo using remote sensing images and geoprocessing techniques. The methodological approach consisted of four steps: a) image restoration and georeferencing; b) non-supervised classification; c) visual interpretation on the computer screen to suppress omission and commission errors; and d) coffee crop area estimation. The results indicated that the applied method was appropriate to map the coffee crop in the states of Minas Gerais and São Paulo.
\end{abstract}

KEYWORDS: remote sensing, satellite images, geoprocessing, agricultural statistics.

\footnotetext{
${ }^{1}$ Projeto Financiado pela CONAB e EMBRAPA CAFÉ.

${ }^{2}$ INPE, Av. dos Astronautas, 1.758, Jardim Granja, São José dos Campos, SP, mauricio@ dsr.inpe.br.

${ }^{3}$ Pesquisador Titular do INPE, Av. dos Astronautas, 1.758, Jardim Granja, São José dos Campos, SP.

${ }^{4}$ INPE, Av. dos Astronautas, 1.758, Jardim Granja, São José dos Campos, SP, aurelio@ dsr.inpe.br.

${ }^{5}$ INPE, Av. dos Astronautas, 1.758, Jardim Granja, São José dos Campos, SP, vivian@ dsr.inpe.br.

${ }^{6}$ INPE, Av. dos Astronautas, 1.758, Jardim Granja, São José dos Campos, SP, adami@ dsr.inpe.br.

Recebido pelo Conselho Editorial em: 13-10-2009

Aprovado pelo Conselho Editorial em: 8-9-2010
} 


\section{INTRODUÇÃO}

O cultivo do café no Brasil apresenta uma grande diversidade de práticas de manejo (com e sem irrigação, com e sem quebra-ventos, etc.), lavouras de diferentes idades, áreas, espaçamentos (tradicional, adensado e superadensado) e variedades (p. ex. Mundo Novo, Catuaí, Acaiá, Icatu e Caturra). Além disso, diferentes condições de clima, relevo, iluminação e época do ano aumentam ainda mais essa diversidade, fazendo com que o café apresente uma significativa variação na resposta espectral gravada em imagens de sensoriamento remoto, o dificultando sua identificação e separação dos demais alvos presentes numa cena.

MOREIRA et al. (2004) observaram que o comportamento espectral da cultura do café nas imagens TM/Landsat-5 está relacionado com o espaçamento, idade da lavoura, topografia do terreno e época do ano em que as imagens foram obtidas. Apesar destas variações observadas, os autores concluíram que é possível identificar e mapear lavouras de café por meio de imagens TM/Landsat-5.

Com base nestes conhecimentos, no ano de 2004, deu-se início a um projeto multidisciplinar e multinstitucional para construir um banco de dados num Sistema Geográfico de Informações referente ao agroecossistema cafeeiro das principais regiões produtoras do Brasil (MOREIRA et al., (2007). Na primeira etapa deste projeto, foi feito o mapeamento da cultura do café no Estado de Minas Gerais (MOREIRA et al., 2007), cujos resultados foram disponibilizados na Internet, em 2006 (http://www.dsr.inpe.br/cafesat). Nesta etapa, contou-se com a colaboração da Companhia Nacional de Abastecimento (CONAB) e da EMBRAPA CAFÉ, por meio do Consórcio Brasileiro de Pesquisa e Desenvolvimento do Café.

Vários estudos vêm abordando diferentes assuntos relacionados ao agroecossistema cafeeiro, entre os quais: as análises espectral e temporal da cultura do café, em imagens TM/Landsat-5 (MOREIRA, 2004); o delineamento do perfil cafeeiro no que se refere à altimetria, à declividade e à posição de vertente (ADAMI et al., 2008); o processo analítico hierárquico na identificação de áreas favoráveis ao cultivo do café em escala municipal (BARROS, 2007); e a análise do potencial de um modelo agrometeorológico-espectral para estimar a produtividade do café (ROSA, 2007). Dentro do contexto destes estudos, o presente trabalho tem por objetivo relatar a metodologia e apresentar os resultados do mapeamento das áreas de café cultivadas nos Estados de Minas Gerais e São Paulo por meio de imagens do sensor TM/Landsat-5 referentes ao ano de 2007.

\section{MATERIAL E MÉTODOS}

A região de estudo compreendeu os Estados de Minas Gerais e de São Paulo, localizados entre as coordenadas $13^{\circ} 49^{\prime} 37^{\prime \prime} \mathrm{S}$ a $24^{\circ} 44^{\prime} 24^{\prime} \mathrm{S}$ e $40^{\circ} 00^{\prime} 37^{\prime \prime} \mathrm{W}$ a $54^{\circ} 00^{\prime} 00^{\prime \prime} \mathrm{W}$. O Estado de Minas Gerais tem 853 municípios (PRODEMGE, 1998), enquanto São Paulo tem 645 municípios (IBGE, 2006).

A cafeicultura em Minas Gerais e em São Paulo ocorre em regiões onde também são cultivadas outras culturas agrícolas, como soja, cana-de-açúcar, cítrus, milho, etc. Para o período em que foram obtidas as imagens do TM/Landsat-5 (junho a outubro), o café é praticamente a única cultura agrícola presente no campo no Estado de Minas Gerais, enquanto em São Paulo o café é cultivado simultaneamente com o milho safrinha, a cana-de-açúcar e cítrus. Contudo, o milho safrinha já se encontra em fase de senescência por ocasião da aquisição das imagens e, portanto, tem resposta espectral bem distinta do café.

A cana-de-açúcar e os cítrus também se diferenciam do café nas imagens adquiridas nesse período (RUDORFF et al., 2005) favorecendo a interpretação e a identificação das lavouras cafeeiras nas imagens do TM/Landsat-5.

A metodologia desenvolvida para mapear as lavouras cafeeiras em nível municipal e, assim, obter a distribuição espacial da cultura é mostrada no fluxograma da Figura 1. 


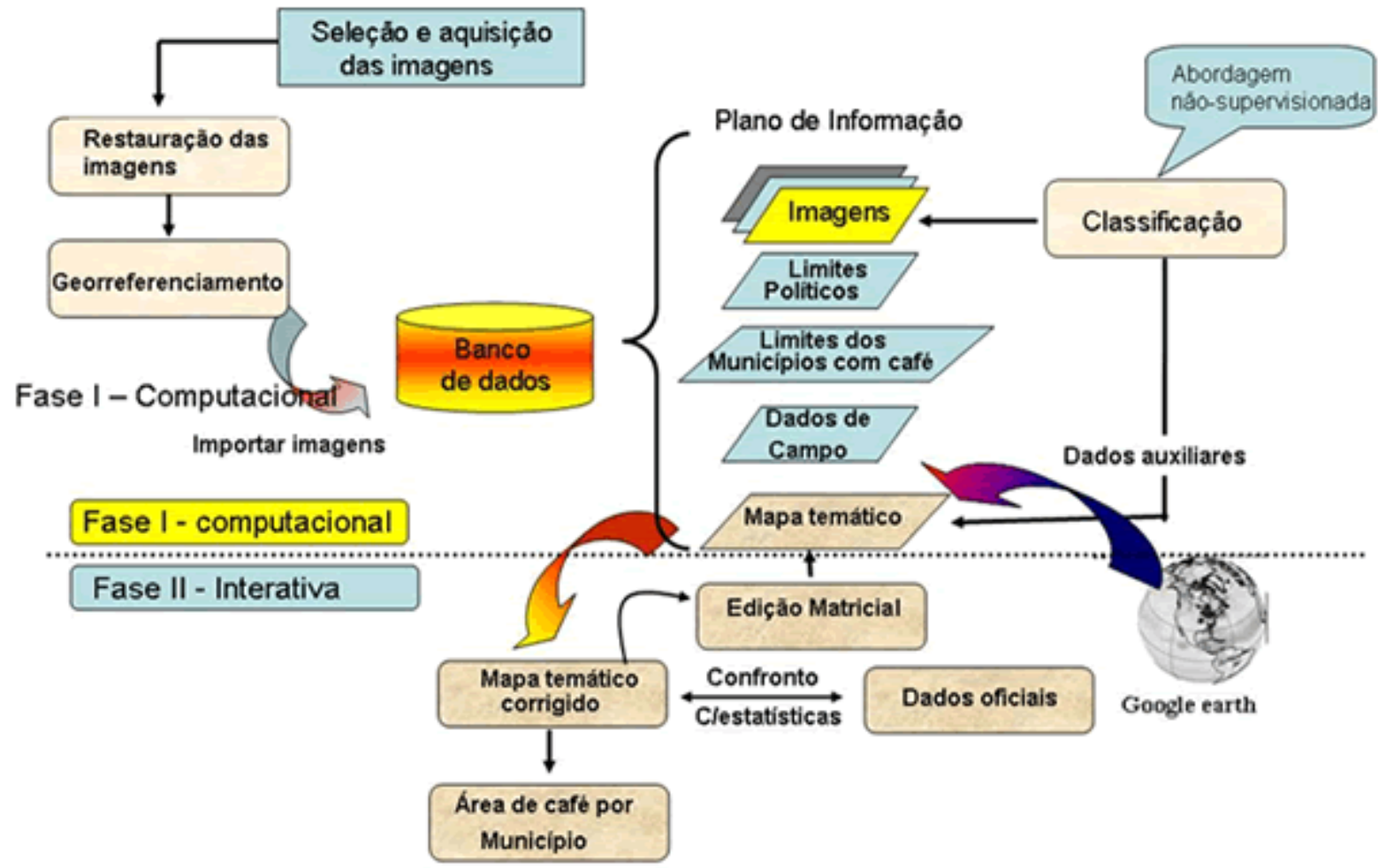

FIGURA 1. Fluxograma mostrando o método empregado na construção do banco de dados geográfico e na interpretação das imagens. Flowchart showing the method used to construct the geographic database and images interpretation.

As estatísticas agrícolas municipais do Levantamento Sistemático da Produção Agrícola LSPA, produzidas pelo Instituto Brasileiro de Geografia e Estatística (IBGE, 2008) sobre a área plantada com café e cítrus auxiliaram na interpretação das imagens. Inicialmente, fez-se um levantamento dos municípios em que o café é cultivado, pois essa informação é relevante para concentrar o trabalho de interpretação nos municípios produtores de café.

As imagens do sensor TM possuem resolução espacial nominal de $30 \mathrm{~m}$, e que nem sempre é adequada para mapeamento de pequenas áreas de café, pois ao ampliar a imagem para uma escala de trabalho maior do que 1:40.000, na tentativa de mapear estas pequenas lavouras, ocorre o realce dos pixels e uma descontinuidade das feições espaciais dos alvos contidos na cena. Isto dificulta a delimitação das lavouras de café de menor área.

Desta forma, as imagens restauradas e com pixels menores do que $30 \mathrm{~m}$ mostraram-se muito úteis no mapeamento do café, pois permitem uma ampliação maior de 1: 40.000, possibilitando melhor definição e delimitação das pequenas lavouras. Segundo FONSECA (1988), a restauração tem o objetivo de reduzir as distorções introduzidas nas imagens causadas pela degradação de sensores, melhorando a resolução espacial efetiva do sensor até certo ponto. Na restauração, é aplicado um filtro linear cujos pesos foram obtidos a partir das características do sensor TM e da posição de suas bandas espectrais. A restauração de imagens TM/Landsat-5 permite obter imagens com resolução espacial de 30;20;15; 10 e 5 m. Uma imagem TM/Landsat-5 restaurada para resolução de $10 \mathrm{~m}$ pode ser ampliada para uma escala de 1:15.000 sem provocar o borramento da imagem causado pelo realce dos pixels (MOREIRA et al., 2007). No projeto de café, a restauração é essencial, e a imagem de saída foi estabelecida em $10 \mathrm{~m}$. No aplicativo SPRING, Versão 4.3.3 (Sistema para Processamento de Informações Georreferenciadas), a restauração das imagens foi feita para as bandas TM3, TM4 e TM5. Após a restauração, as imagens foram georreferenciadas para associar os pixels da imagem a coordenadas geográficas com projeção policônica e datum SAD69. 
Os estados foram divididos em projetos, referenciados pela grade de órbita/ponto do sensor TM. Desta forma, eliminou-se a dependência espacial de uma imagem para outra. A imagem de uma dada órbita/ponto apresenta certo recobrimento com as imagens adjacentes. Para evitar duplicação na interpretação do café, traçou-se a área útil de cada imagem de modo a não haver sobreposição de área a ser mapeada.

O procedimento de edição matricial é feito através de um link dinâmico entre o analista e o computador, que permite visualizar vários Planos de Informação (PIs) ou tipos de informações que foram introduzidas no computador de forma simultânea e interativa. A magnitude desse procedimento depende do resultado da classificação automática. Se o resultado da classificação for satisfatório, então a edição será pouco trabalhosa.

No caso do presente trabalho, a edição matricial foi bastante intensiva devido à semelhança espectral de alguns tipos de cerrado com a cultura do café, conforme anteriormente relatado por MOREIRA al. (2004). É importante ressaltar que as imagens de satélites de alta resolução espacial disponíveis na Internet, no sítio do Google Earth, auxiliaram grandemente na identificação das lavouras cafeeiras do sul/sudoeste de Minas Gerais e de São Paulo. Essas imagens também foram úteis na interpretação das imagens do TM/Landsat-5 de 2007.

Nos locais onde não se dispunha de imagens de alta resolução espacial, as lavouras de café também puderam ser mapeadas com relativa facilidade, haja vista que foi possível caracterizar bem o padrão espectral de lavouras cafeeiras com base nos locais onde havia imagens de alta resolução espacial. Na Figura 2, ilustra-se uma área cafeeira vista nas imagens de alta resolução do Google Earth e nas imagens TM/Landsat-5 (4R5G3B) da região de Machado - MG, para o ano de 2007. Os detalhes das lavouras de café apresentados nas imagens do Google Earth asseguram a correta interpretação nas imagens do TM/Landsat-5.

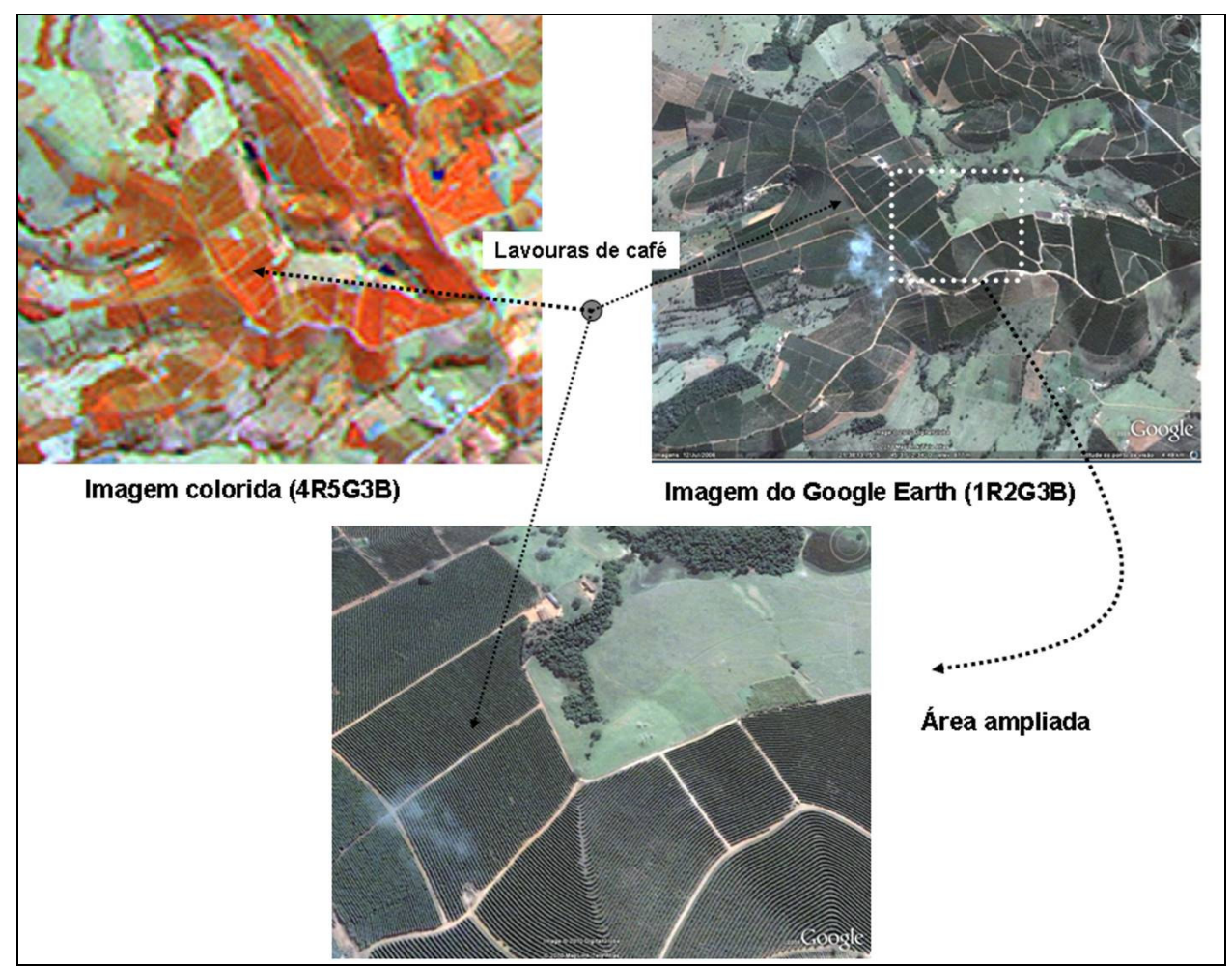

FIGURA 2. Lavoura de café vista numa imagem Ikonos (1B2G3R) do sítio do Google Earth e numa imagem em composição colorida (4R5G3B) do TM/Landsat-5 de 2007. Coffee field seen on an Ikonos image from Google Earth site and on a color composition (4R5G3B) image of TM/Landsat-5 from 2007. 
Após a edição matricial, as avaliações de áreas por município foram comparadas com as informações oficiais do IBGE. Em casos de divergência de área, foi feita uma cuidadosa revisão na interpretação para verificar a ocorrência de possíveis erros de omissão ou inclusão. Nos casos em que a divergência persistia, realizava-se um contato telefônico com técnicos locais ou da Empresa de Assistência Técnica e Extensão Rural do Estado de Minas Gerais (EMATER-MG) ou da Coordenadoria de Assistência Técnica Integral (CATI) do Estado de São Paulo, a fim de obter mais informações para explicar as divergências.

Ao final do processo de edição matricial, foram obtidos mapas temáticos com a distribuição espacial das lavouras cafeeiras. Através de álgebra de mapas entre o mapa temático contendo a distribuição espacial das lavouras cafeeiras e o mapa com os limites municipais de Minas Gerais (PRODEMGE, 1998) ou de São Paulo (IBGE, 2006), foi obtida a área de café em cada município. Esse processo foi realizado por meio da ferramenta "Estatística por Polígono", contida no aplicativo SPRING.

O resultado do mapeamento da área das lavouras de café está disponível por município, mas devido à grande quantidade de municípios (853 para Minas Gerais e 645 para São Paulo) optou-se por apresentar os resultados por Mesorregião.

\section{RESULTADOS E DISCUSSÃO}

Na Figura 3, apresenta-se o mapa temático com a distribuição espacial das lavouras de café por Mesorregião Geográfica do Estado de Minas Gerais. Na Tabela 1, são apresentados os valores das áreas ocupadas com café nas respectivas mesorregiões. Estes valores também são comparados com as estimativas de área colhida de café, realizadas pelo Levantamento Sistemático da Produção Agrícola (LSPA) (IBGE, 2008).

Nota-se que as lavouras cafeeiras se concentram mais em três Mesorregiões: Sul-Sudoeste (46,0\%), Zona da Mata (16,3\%) e Triângulo Mineiro-Alto Paranaíba (16,3\%) que, juntas, respondem por 78,6\% da área cultivada com café no Estado. Para o Estado de Minas Gerais, a área mapeada com café por meio das imagens TM/Lansdat de 2007 foi de 921.203 ha. Em 2006, MOREIRA et al. (2007) utilizaram essa mesma metodologia e encontraram uma área ocupada com café em Minas Gerais, de 930.278 ha, indicando redução de cerca de 1\% (9.075 ha) na área cultivada de 2006 para 2007.

Essa diferença, segundo os autores, foi atribuída principalmente à erradicação de lavouras de café e em parte à poda de lavouras de café. No entanto, os resultados obtidos foram bastante consistentes, o que leva a crer que a área de café em produção no Estado de Minas Gerais está dentro deste valor.

Por outro lado, no Estado de Minas Gerais, foi realizada a validação do mapeamento da cultura do café para o ano de 2007, cujos resultados mostraram que esta metodologia foi muito eficiente na identificação e mapeamento das lavouras de café (ADAMI et al., 2009). Segundo os autores, a exatidão do mapeamento variou de 81 a $99 \%$, em função do percentual da área ocupada com café no estrato. A exatidão geral do mapeamento, ao se integrarem todos os estratos, foi de $95 \%$. 


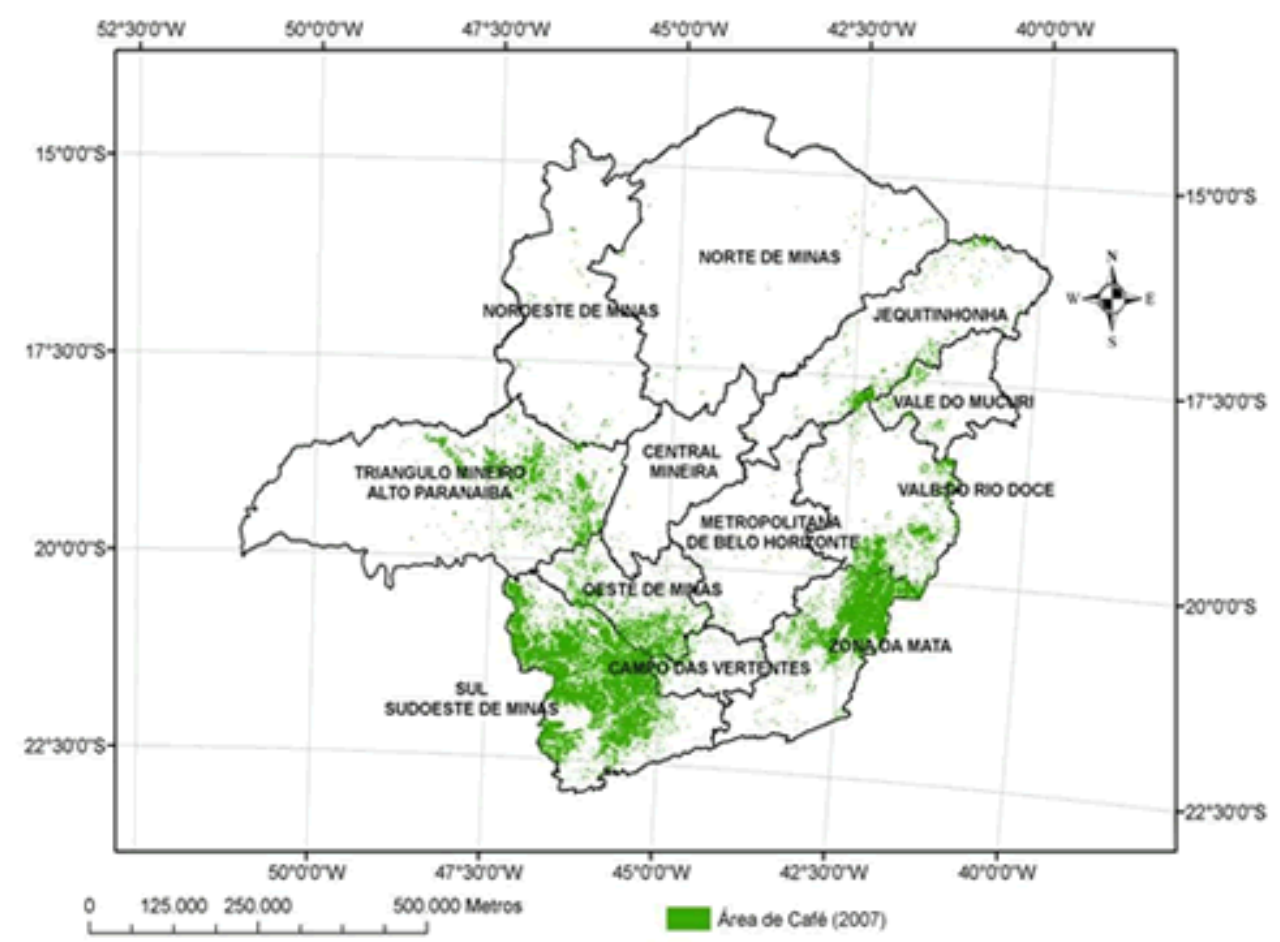

FIGURA 3. Mapa temático mostrando a distribuição espacial das lavouras de café (em verde) por Mesorregião Geográfica do Estado de Minas Gerais para 2007 Thematic map showing the spatial distribution of the coffee fields (green area) by Geographic Regions of Minas Gerais State for 2007.

TABELA 1. Área de café (ha e \%) por mesorregião do Estado de Minas Gerais em 2007. Coffee crop area (ha and \%) by Regions in the State of Minas Gerais in 2007.

\begin{tabular}{lcrrrrr}
\hline \multicolumn{1}{c}{ Mesorregiões } & \multicolumn{7}{c}{ Área de Café (ha) } \\
\cline { 2 - 7 } & Mapeamento & \multicolumn{1}{c}{$\%$} & \multicolumn{1}{c}{ IBGE* } & \multicolumn{1}{c}{ Diferença } & \multicolumn{1}{c}{$\%$} \\
\hline Campo das Vertentes & 23.772 & 2,58 & 27.987 & $2,64 \%$ & -4.215 & $-15,06$ \\
Central Mineira & 729 & 0,08 & 328 & $0,03 \%$ & 401 & 122,26 \\
Jequitinhonha & 22.708 & 2,46 & 31.836 & $3,00 \%$ & -9.128 & $-28,67$ \\
Metropolitana de Belo Horizonte & 2.746 & 0,30 & 3.540 & $0,33 \%$ & -794 & $-22,43$ \\
Noroeste de Minas & 9.534 & 1,03 & 9.898 & $0,93 \%$ & -364 & $-3,68$ \\
Norte de Minas & 6.307 & 0,68 & 8.085 & $0,76 \%$ & -1.778 & $-21,99$ \\
Oeste de Minas & 64.874 & 7,04 & 76.576 & $7,22 \%$ & -11.702 & $-15,28$ \\
Sul/Sudoeste de Minas & 426.146 & 46,26 & 460.143 & $43,40 \%$ & -33.997 & $-7,39$ \\
Triângulo Mineiro/Alto Paranaíba & 150.127 & 16,30 & 143.144 & $13,50 \%$ & 6.983 & 4,88 \\
Vale do Mucuri & 8.992 & 0,98 & 9.778 & $0,92 \%$ & -786 & $-8,04$ \\
Vale do Rio Doce & 55.150 & 5,99 & 87.837 & $8,28 \%$ & -32.687 & $-37,21$ \\
Zona da Mata & 150.117 & 16,30 & 201.115 & $18,97 \%$ & -50.998 & $-25,36$ \\
\hline Total & 921.203 & 100,00 & 1.060 .267 & $100,00 \%$ & -139.065 & $-13,12$ \\
\hline
\end{tabular}

* Fonte: LSPA (IBGE, 2008)

Em comparação com os dados estimados pelo LSPA, pode-se observar que a área observada pelo mapeamento é $13,12 \%$ menor que a área estimada pelo IBGE. As maiores diferenças em área são 33.997, 32.687 e 50.998 ha, para as regiões do sul/sudoeste de Minas, Vale do Rio Doce e Zona da Mata, respectivamente (Tabela 1).

Essa diferença de área pode estar relacionada a questões, por parte do mapeamento, que envolvam tamanho e condições de manejo das lavouras e relevo. Com relação ao LSPA, podem estar relacionadas à forma de levantamento, uma vez que o mesmo é realizado de modo subjetivo, o que não permite inferências sobre estas estimativas. Com relação à Mesorregião Central Mineira, 
apresentou uma diferença percentual de $122,26 \%$ ao comparar o resultado do mapeamento com estatísticas do IBGE, ou seja, a área mapeada mais do que o dobro da área informada pelo IBGE. Em outras palavras, a inclusão de outros tipos de ocupação do solo, como área plantada com café. Esse erro está associado com mapeamento de áreas de reflorestamento novo (padrão espectral parecido com café) e inexistência de imagens de alta resolução no sítio do Google Earth.

Hoje em dia, esse tipo de erro é muito menor, haja vista a qualidade das informações disponíveis no Google Earth.

Para o Estado de São Paulo, o mapa temático contendo a distribuição espacial da cultura do café, em 2007, é apresentado na Figura 4, e o resultado da área cultivada por mesorregião e a comparação com os dados do LSPA (IBGE, 2008) são apresentados na Tabela 2.

Na Figura 4 e na Tabela 2, indicam-se que a maior parte das lavouras de café do Estado de São Paulo se localiza nas mesorregiões de Ribeirão Preto e de Campinas, com 28 e 25\% (Tabela 2), respectivamente, e que nestas duas regiões o café se concentra nos municípios limítrofes à região sul-sudoeste de Minas.

Outras regiões do Estado de São Paulo, que concentram boa parte das lavouras de café, são: Marília (14,20\%), Assis $(9,71 \%)$ e Bauru $(8,42 \%)$. A área total de café mapeada em São Paulo foi de 161.180 ha, que corresponde a apenas 17,5\% da área cultivada com café em Minas Gerais.

No caso de São Paulo, a diferença entre a área mapeada e o estimado pelo LSPA foi maior do que em Minas Gerais. No total, o mapeamento subestimou a área em 22,48\%. As maiores diferenças em área foram de 15.124 e 8.745 ha para as regiões de Campinas e Presidente Prudente, respectivamente.

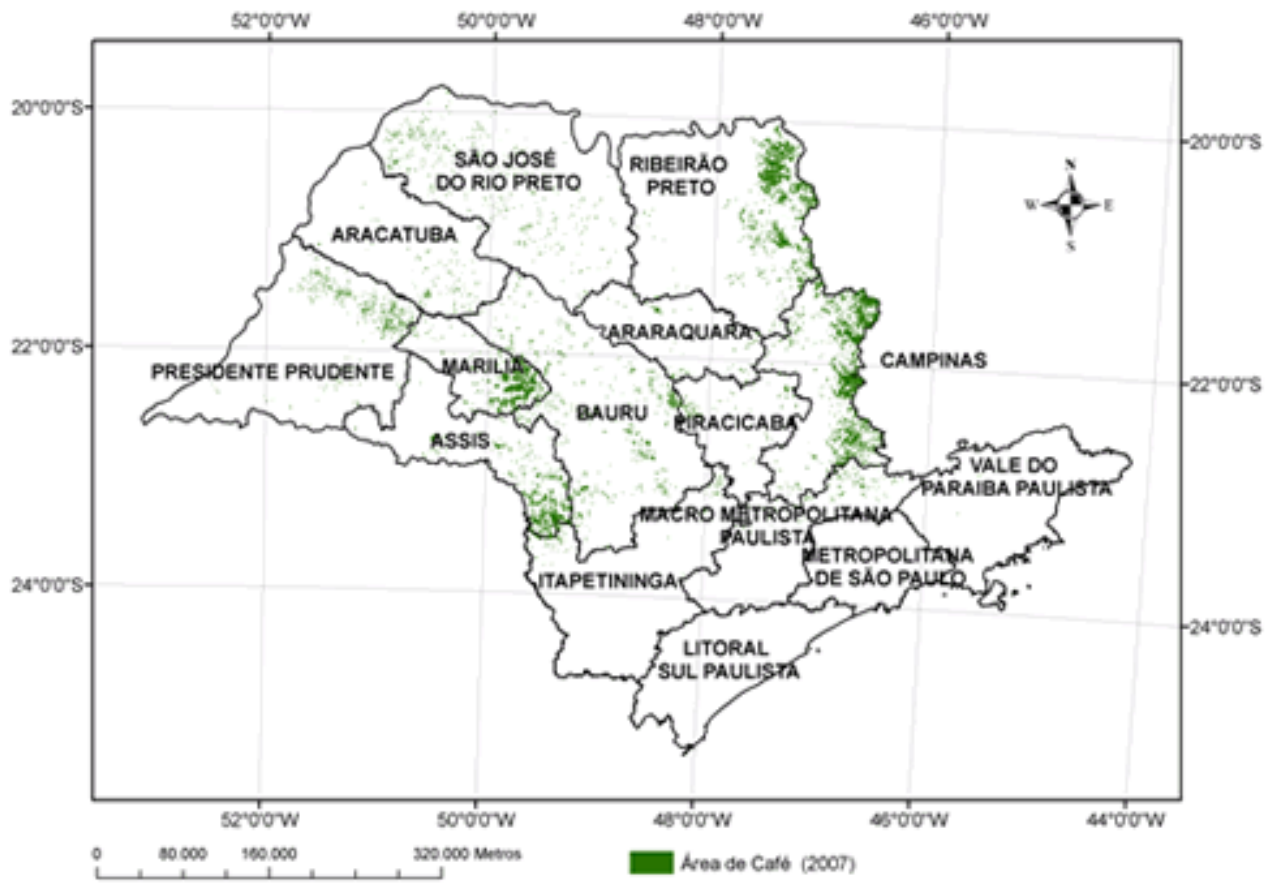

FIGURA 4. Mapa temático mostrando a distribuição espacial das lavouras de café (em verde) por Mesorregião Geográfica do Estado de São Paulo para 2007. Thematic map showing the spatial distribution of the coffee fields (green area) by Geographic Regions in the State of São Paulo in 2007. 
TABELA 2. Área de café (ha e \%) por mesorregião do Estado de São Paulo em 2007. Coffee crop area (ha and \%) by Region in the State of São Paulo in 2007.

\begin{tabular}{lcrrrrr}
\hline \multirow{2}{*}{ Mesorregiões } & \multicolumn{7}{c}{ Área de Café (ha) } \\
\cline { 2 - 7 } & Mapeamento & \multicolumn{1}{c}{$\%$} & \multicolumn{1}{c}{ IBGE* } & \multicolumn{1}{c}{ Diferença } & \multicolumn{1}{c}{$\%$} \\
\hline Araçatuba & 1.536 & 0,95 & 2.552 & 1,23 & -1.016 & $-39,81$ \\
Araraquara & 2.691 & 1,67 & 2.933 & 1,41 & -242 & $-8,25$ \\
Assis & 15.649 & 9,71 & 13.022 & 6,26 & 2.627 & 20,17 \\
Bauru & 13.564 & 8,42 & 21.486 & 10,33 & -7.922 & $-36,87$ \\
Campinas & 40.759 & 25,29 & 55.883 & 26,88 & -15.124 & $-27,06$ \\
Itapetininga & 1.968 & 1,22 & 2.712 & 1,30 & -744 & $-27,43$ \\
Litoral Sul Paulista & 29 & 0,02 & 0 & 0,00 & 29 & 0,00 \\
Macro Metropolitana & 1.849 & 1,15 & 2.796 & 1,34 & -947 & $-33,87$ \\
Paulista & 22.892 & 14,2 & 26.544 & 12,77 & -3.652 & $-13,76$ \\
Marília & 0 & 0 & 0 & 0,00 & 0 & 0,00 \\
Metropolitana de São Paulo & 2.349 & 1,46 & 2.976 & 1,43 & -627 & $-21,07$ \\
Piracicaba & 4.887 & 3,03 & 13.632 & 6,56 & -8.745 & $-64,15$ \\
Presidente Prudente & 45.883 & 28,47 & 52.958 & 25,47 & -7.075 & $-13,36$ \\
Ribeirão Preto & 6.945 & 4,31 & 10.128 & 4,87 & -3.183 & $-31,43$ \\
São José do Rio Preto & 178 & 0,11 & 292 & 0,14 & -114 & $-39,04$ \\
Vale do Paraíba Paulista & 161.180 & 100,00 & 207.914 & 100,00 & -46.734 & $-22,48$ \\
\hline TOTAL & & & & &
\end{tabular}

* Fonte: LSPA (IBGE, 2008)

O uso de imagens restauradas do TM/Landsat-5 no mapeamento de áreas de café foi muito útil, pois permitiu ampliar as imagens para escala de 1:20.000 ou mais sem que os pixels fossem realçados, conforme mostrado na Figura 5.

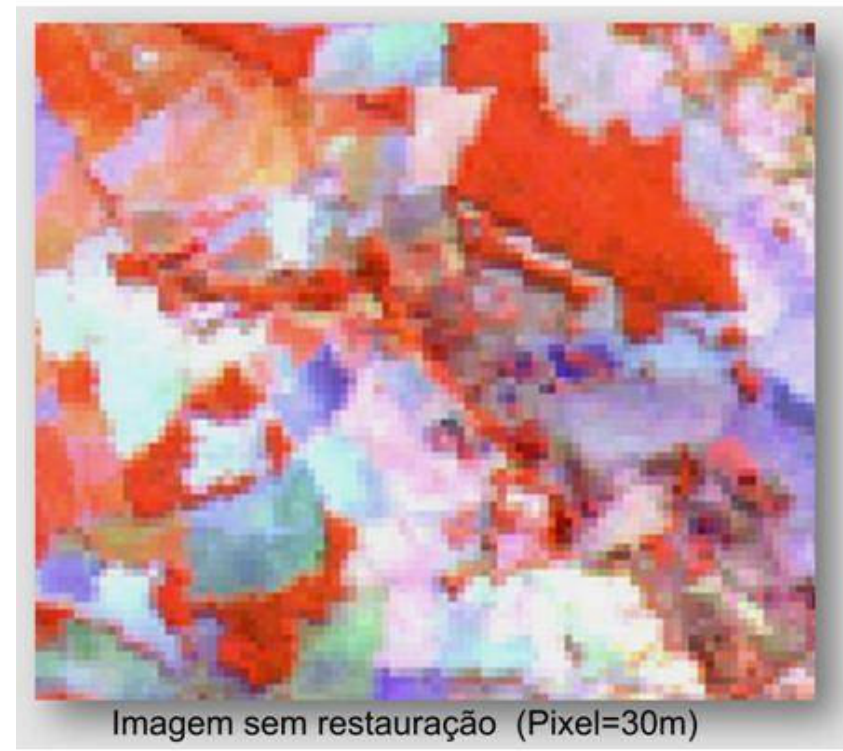

FIGURA 5. Parte de uma imagem TM/Landsat-5 em composição colorida (4R5G3B) sem restauro (à esquerda) e restaurada (à direita). Part of a TM/Landsat-5 image in color composition (4R5G3B) without restoration (left) and restored (right).

Contudo, mesmo com a restauração das imagens, as lavouras novas de cafezal com menos de 2 anos não puderam ser identificadas, pois apresentam resposta espectral de solo exposto nas imagens, conforme mostrado na Figura 6. 


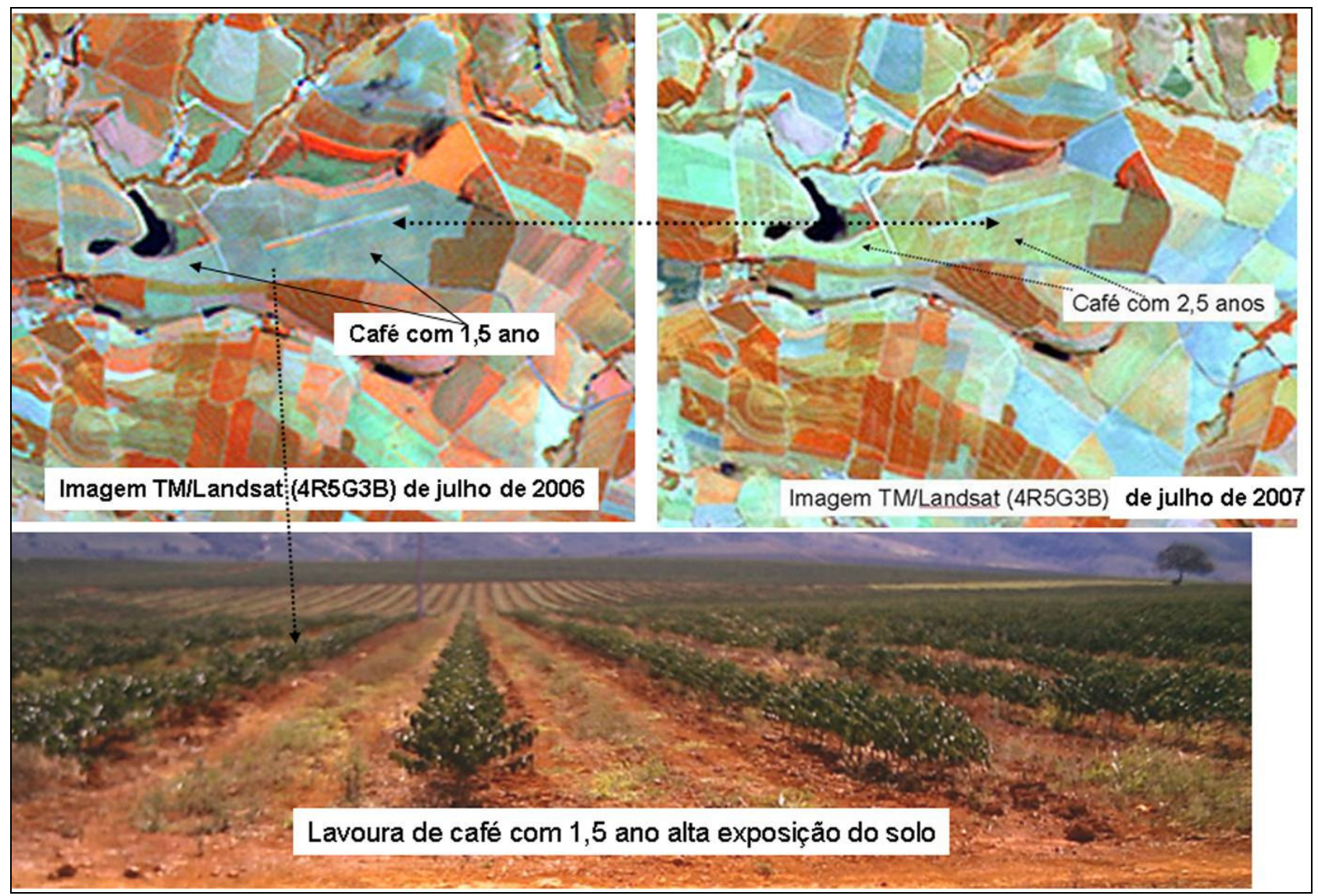

FIGURA 6. Imagem do TM/Landsat-5 (4R5G3B) obtida em julho de 2006, mostrando as lavouras novas de café (cerca de 1,5 ano de idade) com aparência de solo exposto e outra imagem de julho de 2007, mostrando as mesmas lavouras com padrão espectral de lavoura de café. TM/Landsat-5 image (4R5G3B) acquired in July of 2006 showing new coffee fields (about 1.5 years old) with bare soil appearance and another image from July of 2007 showing the same fields with spectral pattern of coffee fields.

Durante a interpretação, notou-se que várias áreas identificadas nas imagens Ikonos de 2003 e 2004 do sítio do Google Earth como lavouras de café não puderam ser identificadas nas imagens de 2007 do TM/Landsat-5.

Entre as causas mais comuns desta mudança podemos citar: a poda da lavoura, ficando a mesma com aparência de solo exposto; a reforma da lavoura; e a substituição por outras culturas, principalmente pela cana-de-açúcar em São Paulo.

Em regiões de relevo acidentado, como na Zona da Mata mineira, observou-se que imagens obtidas com ângulo solar mais alto são mais indicadas, pois o efeito de sombreamento provocado pelo relevo diminui com o aumento do ângulo de elevação solar, conforme mostrado na Figura 7. 


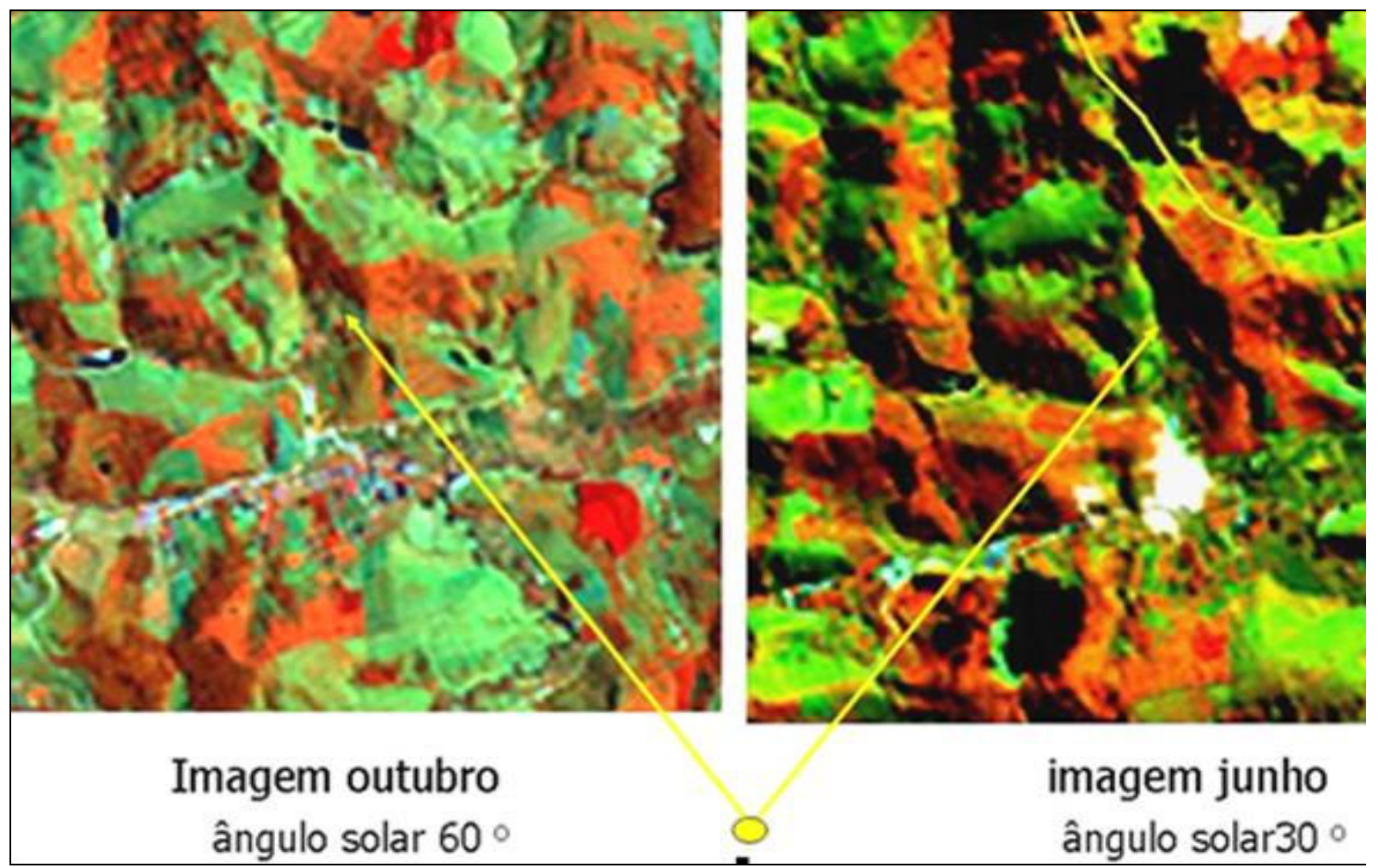

FIGURA 7. Imagens do TM/Landsat-5 da Zona da Mata de Minas Gerais obtidas em junho e em outubro de 2007, mostrando o efeito de sombreamento do relevo causado pelo ângulo de elevação solar. TM/Landsat-5 images, from the Zona da Mata in Minas Gerais, acquired in June and October of 2007 showing the shading effect due to the relief caused by the solar elevation angle.

As lavouras de café com idade maior do que 2,5 anos apresentaram comportamento espectral característico da cultura e a superfície de fundo teve pouca influência na resposta espectral. Para a maioria das lavouras de café, quando observadas em imagens TM na composição colorida (4R5G3B), elas se apresentaram com um matiz marrom, marrom mais avermelhado ou esverdeado, dependendo da participação da superfície de fundo na resposta espectral da lavoura.

As lavouras que apresentaram matizes mais avermelhadas podem ser confundidas com o cerrado (stricto sensu) por questão da semelhança de comportamento espectral (Figura 8), conforme já relatado por MOREIRA et al. (2004). Dada esta característica espectral, a classificação automática, inevitavelmente, irá agrupar as duas classes (cafeeiros e cerrado stricto sensu).

As variações no comportamento espectral das lavouras de café são ocasionadas principalmente por diferença de espaçamento, que aumenta ou diminui a participação da superfície de fundo e de condições fitossanitárias da cultura, concordando com os autores supracitados. 


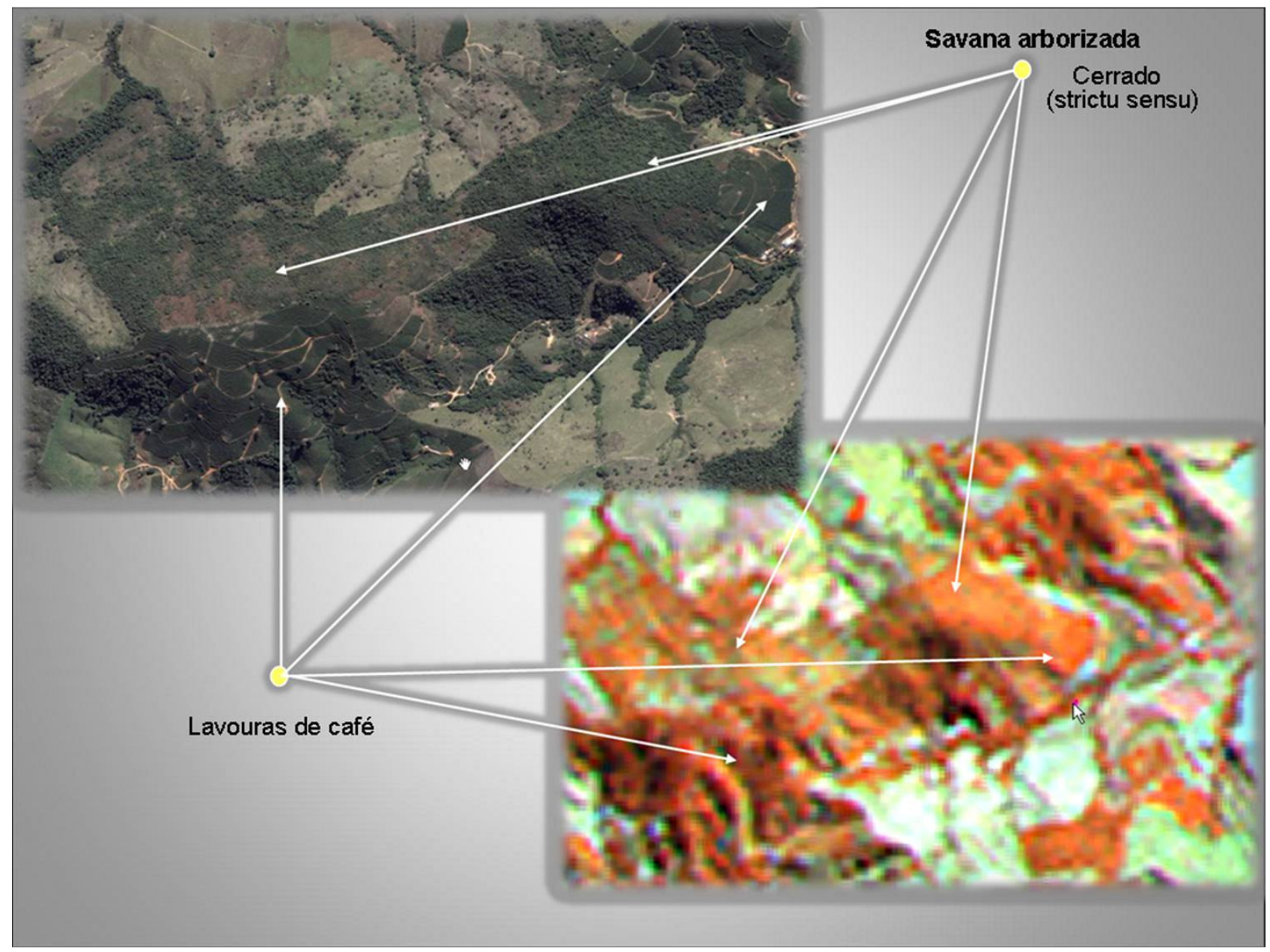

FIGURA 8. Aparente semelhança entre o cerrado (stricto sensu) e a cultura do café em imagens TM/Landsat-5 em composição colorida (4R5G3B). Apparent similarity between cerrado (Strictu sensu) and coffee crop in TM/Landsat-5 images of color compositions (4R5G3B).

Para as lavouras implantadas com o sistema de quebra-vento, ocorre um padrão espectral e o arranjo espacial típico, conforme é mostrado na Figura 9, onde as linhas em marrom-escuro se referem às linhas arbóreas intercaladas nos talhões da cultura.

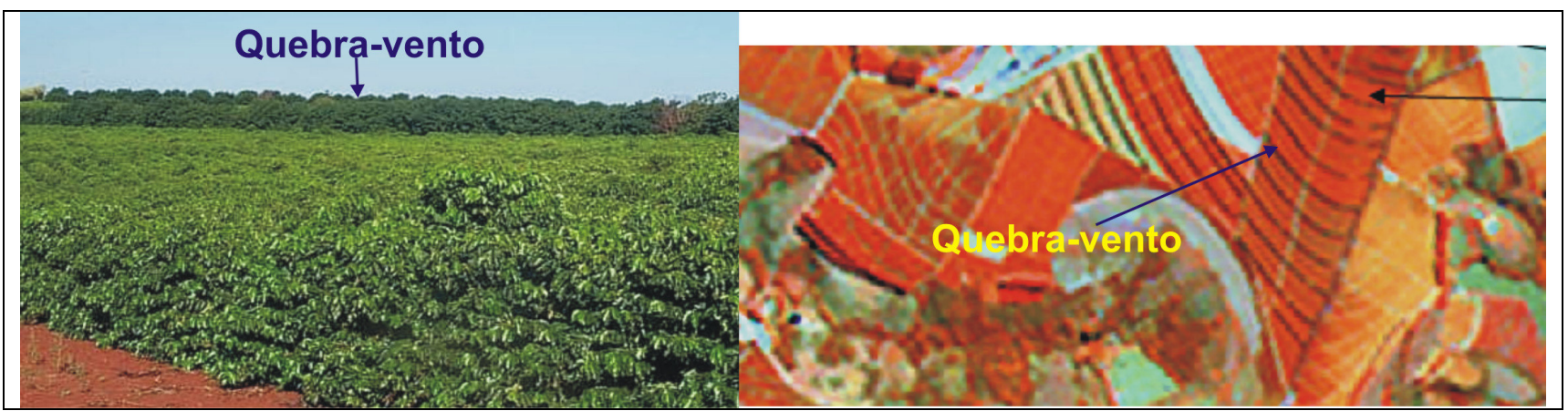

FIGURA 9. Lavoura de café com barreira de quebra-ventos ao fundo (à esquerda) e aparência dos quebra-ventos nas lavouras de café na imagem TM/Landsat-5 (à direita). Coffee crop with barrier against the wind in the back (left side) and appearance of the windbreak in the TM/Landsat-5 image (right side). 
Na Figura 10, apresentam-se diversos padrões de lavouras de café encontrados numa mesma região. As lavouras irrigadas por pivô central têm padrão bem típico pelo fato de as linhas de plantio serem concêntricas. No norte de Minas Gerais, encontram-se com frequência lavouras de café irrigadas por pivô central e que contrastam com os demais alvos presentes na imagem.

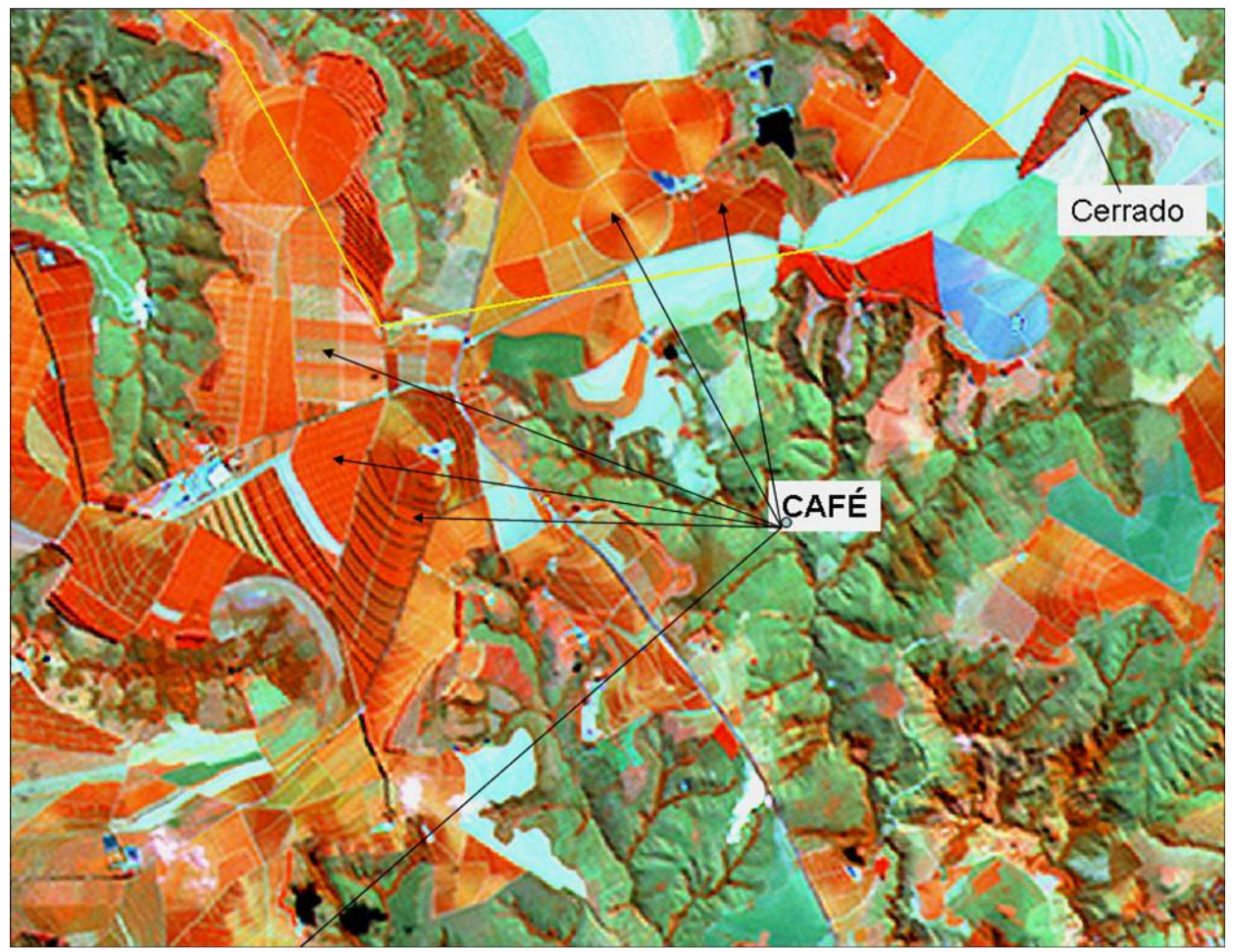

FIGURA 10. Imagem TM/Landsat-5 em composição colorida (4R5G3B) restaurada, ilustrando diferentes padrões de lavouras de café devido aos diferentes sistemas de plantio. Restored TM/Landsat-5 image in color composition (4R5G3B) illustrating different patterns of coffee fields due to different planting systems.

\section{CONCLUSÕES}

A metodologia utilizada possibilitou identificar e mapear as áreas de café cultivadas nos Estados de Minas Gerais e São Paulo, utilizando imagens de sensoriamento remoto e técnicas de geoprocessamento. A restauração das imagens TM/Landsat-5 permitiu ampliá-las para uma escala em torno de 1:20.000, o que favoreceu a identificação e a delimitação de pequenas lavouras de café. A melhor época de aquisição das imagens para o mapeamento do café em Minas Gerais está no período seco (junho a setembro).

Para o Estado de São Paulo, esse período é mais restrito (agosto a setembro) devido ao cultivo do milho safrinha. O uso das imagens de alta resolução espacial no sítio do Google Earth foi de extrema valia, diminuindo grandemente a necessidade de trabalho de campo para dirimir as dúvidas durante a interpretação. Foi possível mapear as lavouras de café com idade maior ou igual a 2,5 anos.

\section{REFERÊNCIAS}

ADAMI, M.; MOREIRA, M.A.; BARROS, M.A.; MARTINS, V.A.; RUDORFF, B.F.T. Avaliação da exatidão do mapeamento da cultura do café no Estado de Minas Gerais. In: SIMPÓSIO

BRASILEIRO DE SENSORIAMENTO REMOTO, 14., 2009, Natal. Anais... São José dos Campos: INPE, 2009. p.1-8. 
ADAMI, M.; BARROS, M.A.; MOREIRA, M.A.; RUDORFF, B.F.T. Caracterização da cafeicultura mineira em função da altimetria, declividade e orientação de vertentes como subsídio ao planejamento agrícola, em escala regional. In: SIMPOSIO SELPER, 13., 2008, Havana. Anais...

BARROS, M.A. Geotecnologias como contribuição ao estudo do agroecossistema cafeeiro de Minas Gerais em nível municipal. São José dos Campos: Instituto Nacional de Pesquisas Espaciais, 2007. 159 p. (INPE-14591-TDI/1177).

FONSECA, L.M.G. Restauração de imagens do satélite Landsat-5 por meio de técnicas de projeto de filtros FIR. São José dos Campos, 1988. 148 f. Dissertação (Mestrado em Engenharia Eletrônica) - Instituto Tecnológico de Aeronáutica, São José dos Campos, 1988.

IBGE. INSTITUTO BRASILEIRO DE GEOGRAFIA E ESTATÍSTICA. Cidades. Disponível em: <http://www1.ibge.gov.br/cidadesat/default.php>. Acesso em: 12 fev. 2007.

IBGE. INSTITUTO BRASILEIRO DE GEOGRAFIA E ESTATÍSTICA. Geociências. Disponível em: <ftp://geoftp.ibge.gov.br/mapas/malhas_digitais/municipio_2005/E500/Proj_Policonica/>. Acesso em: 26 jul. 2006.

IBGE. INSTITUTO BRASILEIRO DE GEOGRAFIA E ESTATÍSTICA. Levantamento sistemático da produção agrícola. Disponível em: <

http://www.ibge.gov.br/home/estatistica/indicadores/agropecuaria/lspa/default.shtm >. Acesso em: 2 mar. 2008.

INPE. INSTITUTO NACIONAL DE PESQUISAS ESPACIAIS. Catálogo de imagens. São José dos Campos: INPE, 2005. Disponível em: <http://www.dgi.inpe.br/CDSR>. Acesso em: 20 maio 2006.

MOREIRA, M.A.; ADAMI, M.; RUDORFF, B.F.T. Análise espectral e temporal da cultura do café em imagens Landsat-5. Pesquisa Agropecuária Brasileira, Brasília, v.39. n.3, p.223-231. 2004.

MOREIRA, M.A.; BARROS, M.A.; ROSA, V.G.C.; ADAMI, M. Tecnologia de informação: imagens de satélite para o mapeamento de áreas de café de Minas Gerais. Informe Agropecuário, Belo Horizonte, v.28, n.241, p.27-37, 2007.

MOREIRA, M.A.; RAFAELLI, R.D.; BARROS, M.A.; FARIA, V.G.C. de; AULICINO, T.L.I.N.; CARVALHO, M.A. de. Uso da Geotecnologia para avaliar e monitorar a cafeicultura brasileira: Fase I - Estado de Minas Gerais. São José dos Campos: Instituto Nacional de Pesquisas Espaciais, 2007. 88 p. (INPE-14611-RPE/808).

PRODEMGE. COMPANHIA DE TECNOLOGIA DA INFORMAÇÃO DO ESTADO DE MINAS GERAIS. Limite dos Municípios de Minas Gerais. Belo Horizonte, 1998. Disponível em: <http:// www.geominas.mg.gov.br/>. Acesso em: 15 mar. 2007

ROSA, V.G.C. Modelo agrometeorológico-espectral para monitoramento e estimativa da produtividade do café na Região Sul/Sudoeste do Estado de Minas Gerais. São José dos Campos: Instituto Nacional de Pesquisas Espaciais, 2007. 143 p. (INPE-14791-TDI/1234).

RUDORFF, B.F.T.; BERKA, L.M.S.; MOREIRA, M.A.; DUARTE, V.; XAVIER, A.C. ; ROSA, V.G.C. ; SHIMABUKURO, Y.E. Imagens de satélite no mapeamento e estimativa de área de canade-açúcar em São Paulo: ano safra 2003/04. Agricultura em São Paulo (Impresso), São Paulo, v.52, n.1, p.21-39, 2005. 